\title{
POLA NOUN PHRASE YANG UMUM DITEMUKAN DALAM ABSTRAK ARTIKEL PENELITIAN
}

\author{
Nurul Frijuniarsi \\ Program Studi Informatika, Fakultas Teknik dan Ilmu Komputer \\ Universitas Indraprasta PGRI \\ frijuniarsinurul@gmail.com
}

\begin{abstract}
Abstrak
Tujuan dari penelitian ini adalah untuk mengidentifikasi variasi jenis pola kombinasi kata yang membentuk noun phrase serta mengetahui pola seperti apa yang cenderung paling banyak digunakan. Metode yang digunakan adalah studi pustaka dengan pendekatan deskriptif kualitatif. Data diperoleh dari abstrak yang terdapat pada jurnal ARTESOLESP E-journal. Volume 2, No. 1, November 2012 ISSN 1853-7693. Hasil analisis menunjukkan bahwa pola noun phrase yang digunakan dalam abstrak tersebut sangat variatif yaitu sebanyak 38 variasi dari total 65 data, sedangkan jenis pola kombinasi kata yang paling sering digunakan adalah pola sederhana ( kombinasi 1 - 3 kata) dengan total 39 data atau $60 \%$ dari total keseluruhan, dengan jenis kombinasi kelas kata (part of speech) yang paling banyak digunakan adalah adjective + noun sebanyak 8 item atau $12.31 \%$ dari total noun phrase.
\end{abstract}

Kata Kunci: Pola Noun Phrase, Kelas Kata

\begin{abstract}
The aims of this study are to identify the variation of words combination pattern in composing noun phrase as well as to figure out the most frequently used pattern. Library research method and descriptive qualitative approach are applied on this study. The data were taken from the abstracts ARTESOLESP Ejournal. Volume 2, No. 1, November 2012 ISSN 1853-7693. The result shows that the noun phrase pattern written in those abstracts are various where there are 38 verities of word combinations of 65 noun phrases. While the most frequently used pattern is the simple pattern, in which 1 to 3 words are combined, with 39 numbers of data or $60 \%$ of total numbers of noun phrase. While the most dominant part of speech combination used in forming noun phrases is the combination of adjective+noun with 8 item or $12.31 \%$ of the whole.
\end{abstract}

Key Words: Noun Phrase Patterns, Part of Speech

\section{PENDAHULUAN}

Penggunaan bahasa dalam keseharian berbeda-beda tergantung dari berbagai faktor yang mempengaruhi, misalnya kapan, dimana, dan untuk tujuan apa bahasa tersebut digunakan. Ketika orang-orang berinteraksi dengan santai dalam percakapan sehari-hari, mereka cenderung menggunakan kata-kata yang lebih sederhana dan gampang dimengerti, namun ketika orang-orang berbahasa untuk tujuan atau situasi yang lebih formal seperti hal nya dalam seminar, workshop, professional meeting, diskusi kelas, pembacaan berita, ataupun situasi formal lainnya, kata-kata yang digunakan pun akan lebih beragam dan pemilihan diksinya pun akan disesuaikan dengan konteks atau topik pembicaraan yang umumnya bersifat informatif dan juga intelek. Sepertihalnya bahasa tutur, bahasa yang 
digunakan dalam ragam tulis juga dipengaruhi oleh berbagai faktor seperti yang telah disebutkan sebelumnya. Seringkali ketika kita membaca sebuah surat pribadi yang ditulis oleh seseorang untuk teman dekat ataupun seorang kerabat, kita hanya membutuhkan sedikit waktu untuk memahami keseluruhan isi dan pesan yang disampaikan dalam surat tersebut, hal itu dikarekan oleh pemilihan kata yang sederhana yang digunakan oleh si penulis surat dalam mengekspresikan pikirannya.

Namun situasi yang berbeda akan kita temukan saat membaca sebuah artikel baik di jurnal maupun majalah, materi prsentasi ataupun semiar, atau saat membaca buku materi perkuliahan. Kita akan membutuhan waktu yang lebih banyak untuk mencerna dan menyerap informasi yang disampaikan melalui kata-kata, frasa, dan kalimat yang tertulis dalam mediamedia tersebut. Penggunaan frasa sebagai bagian dari sebuah kalimat utuh dalam bidang akademik, jurnalis, maupun bidang profesional yang lain akan lebih rumit dan variatif dibandingkan dengan frasa yang digunakan dalam surat pribadi, catatan harian ataupun bacaan ringan semacam novel fiksi remaja.

Frasa nomina (noun phrase) sebagai salah satu unsur penyusun kalimat memiliki peranan yang penting dalam penyampain isi kalimat, baik itu dalam tulisan non-formal ataupun tulisan formal, karena frasa nomina (noun phrase) berfungsi sebagai subjek dan objek dalam sebuah kalimat, bahkan tak jarang frasa nomina (noun phrase) digunakan sebagai keterangan apabila didahului oleh preposisi. Yang membedakannya adalah bentuk-bentuk frasa nomina yang kita temukan di artikel sebagai contoh, akan lebih beragam dalam segi komponen kata penyusun frasa nomina tersebut, baik disadari maupun tidak. Berdasarkan uraian di atas maka penulis tertarik untuk menganalisi kecenderungan pola frasa nomina (noun phrase) yang digunakan dalam sebuah ragam tulisan formal, yaitu abstrak berbahasa Inggris yang terdapat di berbagai artikel dan jurnal akademik. Adapun batasan jenis abstrak yang penulis analisis adalah abstrak dari penelitian dalam bidang bahasa.

\section{Hakikat English Noun Phrase}

Sebuah frasa sebagai unsure pembentuk sebuah kalimat biasanya terdiri dari dua atau lebih kata yang digabungkan untuk membentuk makna yang lebih khusus dari sebuah kata yang menjadi "head" atau kata utama dari frasa tersebut, dan penamaan dari frasa juga tergantung dari kata yang dijadikan kata utama atau "head" tersebut. Noun phrase, sebagaimana namanya memiliki noun atau nomina sebagai inti nya. Dalam sebuah kalimat, khususnya kalimat berbahasa Inggris, noun phrase memiliki fungsi sebagai subjek ataupun objek. Sebuah kalimat yang tidak memiliki subjek tidak bisa diklasifikasikan sebagai sebua kalimat, kecuali kalimat tersebut adalah imperatif yang subjeknya bersifat implisit dan tidak perlu disebutkan karena partisipannya sudah mengetahui siapa subjek yang dimaksudkan. Bentuk kalimat ini biasanya lebih sering ditemui dalam ragam bahasa tutur. Diungkapkan oleh Jacobs in Carnie (2012) bahwa noun phrase digunakan ketika seseorang ingin merujuk sebuah hal sehingga tak jarang noun phrase menjadi topik dari sebuah kalimat atau bacaan. Sebuah noun phrase bisa saja terdiri hanya dari sebuah konstituen dari sebuah elemen, misalnya pada kata "books" namun terkadang seringnya 
lebih kompleks. Sebuah noun phrase sederhana bisa dibentuk dengan mengombinasikan sebuah article atau determiner dengan sebuah noun sebagai topiknya. Chomsky seperti yang dikutip oleh Carnie (2012) menyatakan: Phrases contain two or more words combine together with a certain word as the central idea...... and as larger part of sentence, clause consists of subject and predicate but only functions as additional information in a sentence, it can't stand by itself as sentence does. Berdasarkan penjelasan di atas maka kita dapat menyimpulkan konsep dasar dari sebuah noun phrase, sebuah noun ohrase haruslah memiliki sebuah nomina (noun) sebagai inti (head) dan kata-kata pendukung lainnya yang disebut modifier, namun sebuah noun phrase bisa saja hanya terdiri dari sebuah noun atau pronoun.

\section{Bentuk-bentuk Noun Phrase}

Selain terdiri dari sebuah kata, noun phrase bisa dibentuk dengan menggabungkan dua kata atau lebih (Jacobs in Carnie, 2012). Berikut ini beberapa kombinasi kata yang bisa digunakan untuk menbentuk sebuah noun phrase. Catatan: nomina (noun) yang berfungsi sebagai inti dari noun phrase ditandai dengan $\mathrm{H}$ (head) sedangkan kata lain yang berfungsi sebagai pendukung ditandai dengan $\mathrm{M}$ (modifier)

1. Article

(definite/indefinite/demonstrative)

+ Noun

Cth: $\quad \underline{\text { A house }} \quad$ (indefinite article + noun)

$$
M \quad H
$$

$$
\text { (definite article } \frac{\underline{T h e}}{+ \text { noun) }}
$$

2. Demonstrative + Noun

$$
\text { Cth: } \quad \frac{\text { This }}{M} \frac{\text { country }}{H}
$$

3. Quantifier + Noun

Cth: $\quad \frac{\text { Many people }}{M}$

$\frac{\text { Some }}{M} \frac{\text { questions }}{H}$

$\frac{\text { Less }}{M} \frac{\text { sugar }}{H}$

4. Possessive + Noun

$\begin{aligned} \text { Cth: } & \frac{\text { My }}{M} \frac{\text { parents }}{H} \\ & \frac{\text { Their }}{M} \frac{\text { teacher }}{H} \\ & \frac{\text { Toni's }}{M} \frac{\text { sister }}{H}\end{aligned}$

(Article, quantifier, possessive, dan demonstrative dikelompokkan dalam sebuah grup yang disebut determiner)

5. Numeral + Noun

$\begin{aligned} \text { Cth: } \quad & \frac{\text { Two }}{M} \frac{\text { women }}{H} \\ & \frac{\text { Four }}{M} \frac{\text { dictionaries }}{H}\end{aligned}$

6. Noun + Noun

Cth: $\quad \frac{\text { Birthday }}{M} \frac{\text { gift }}{H}$

$\frac{\text { English }}{M} \frac{\text { book }}{N}$

7. Adjective + Noun

Cth: $\quad \frac{\text { Old }}{M} \frac{\text { poetry }}{H}$

$\frac{\text { Smart thought }}{M} \frac{\text { th }}{H}$

8. Article + Adjective + Noun

Cth: $\quad \frac{\text { The beautiful song }}{M} \frac{\text { song }}{H}$

$\underline{A n} \frac{e a s y}{M a y}$

$M \quad M \quad \frac{A}{H}$

9. Article + Adverb + Adjective + Noun

Cth: $\quad \frac{\text { A very }}{M} \frac{\text { hard decision }}{M} \frac{\text { de }}{H}$

$\underline{\text { A really }} \underline{\text { nice }} \underline{\text { vacation }}$

$H$ 


10. Quantifier/
Demonstrative + Adjectiveral
Noun
Cth: $\quad \frac{\text { Some }}{M} \frac{\text { pretty }}{M} \frac{\text { girls }}{H}$
$\frac{\text { Five }}{M} \frac{\text { high }}{M} \frac{\text { buildings }}{H}$
$\frac{\text { This }}{M} \frac{\text { sweet }}{M} \frac{\text { cake }}{H}$

Kombinasi kata di atas hanya lah sebagian contoh kemungkinan yang dapat ditemukan dalam pola noun phrase, dengan kata lain dapat disimpulkan bahwa noun phrase bisa terdiri dari dua kalimat atau lebih bisa dibentuk dari berbagai kategori atau kelas kata yang tentu saja dikombinasikan dengan noun sebagai inti dari frasa.

\section{Pola Noun Phrase Berdasarkan Diagram Pohon (Tree Diagram)}

Seperti yang sudah disinggung sebelumnya noun phrase merupakan satu dari dua komponen utama sebuah kalimat, bersama dengan verb phrase. Dalam konsep Tree Diagram, keduanya berfungsi sebagai konstituen dengan tingkatan yang tinggi dalam struktur kalimat. Istilah konstituen dalam konsep Diagram Pohon (Tree Diagram) merupakan hasil dari kolaborasi ketiga properti dasar dari struktur kalimat, yaitu linearitas, hirarki, dan kategori (Jacobs in Carnie, 2012). Noun phrases yang bertindak sebagai subjek kalimat menempati posisi yang lebih tinggi dibandingkan noun phrase yang berfungsi sebagai objek.

Dalam beberapa kasus, terkadang noun phrase juga terdiri dari prepositional phrase. Berikut contoh noun phrase yang mengandung prepositional phrase di dalamnya dapat dilihat pada kalimat-kalimat berikut ini:

1. We discussed the change of plan last night.
2. I have read the story about criminality many times.

3. This is our last meeting before long holiday.

4. Her parents have prepared $\underline{a}$ surprise party for her birthday.

5. When I was child, the thing I'd been always waiting for is the rainbow after rain.

6. According to the local urban legend, the house at the edge of this road are haunted.

7. My favorite seat on the plane is the one beside the window.

Noun phrase dalam sebuah kalimat terdapat dalam beberapa posisi tertentu. Menurut Aitchison (2003) beberapa posisi dalam sebuah kalimat yang sering diidentifikasi keberadaan noun phrase adalah: (1) Di awal kalimat sebelum kata kerja (verb); The cat ate the canary. (2) Di akhir kalimat setelah kata kerja; The canary feared the cat. (3) Setelah kata 'by' dalam kalimat pasif; The canary was eaten by the cat. (4) Setelah auxiliary verb dalam kalimat tanya; Did the cat eat the canary?

Berdasarkan uraian di atas dapat ditarik kesimpulan bahwa dipandang dari segi linearitas, hirarki, dan kategori yang terkandung dalam konsep Tree Diagram, noun phrase memiliki derajat dan posisi yang tinggi dalam sebuah kalimat, terutama jika ia berfungsi sebagai subjek kalimat.

\section{METODE PENELITIAN}

Dalam pelaksanaannya, penelitian ini menggunakan pendekatan deskriptif kualitatif dan metode studi pustaka. Adapun data yang diolah dan dianalisis merupakan sejumlah noun phrase yang terdapat dalam abstrak bahasa Inggris pada beberapa artikel penelitian di 
bidang bahasa yang berasal dari ARTESOLESP E-journal. Volume 2, No. 1, November 2012 ISSN 18537693, sebuah Jurnal terbitan TESOL International Association Argentina. Data dikumpulkan untuk kemudian dianalisis polanya berdasarkan kategori kelas kata penyusunnya. Lalu dikelompokkan berdasarkan jumlah kata penyusun menjadi Noun Phrase Pola Sederhana (noun phrase yang terdiri dari 1 sampai 3 kombinasi kata) dan Noun Phrase Pola Komples (noun phrase yang terdiri dari 4 kata atau lebih). Perhitungan sederhana dengan menggunakan presentasi diterapkan untuk mengetahui pola noun phrase apa yang paling banyak digunakan dalam abstrak pada Jurnal tersebut. Total terdapat 65 data noun phrase yang terdapat pada empat abstrak.

\section{HASIL DAN PEMBAHASAN}

Terdapat 65 data temuan noun phrase yang kemudian dikelompokkan berdasarkan kesamaan pola susunan kata-katanya. Adapun klasifikasi kata yang menjadi dasar pengelompokkan adalah sembilan kelas kata dalam bahasa Inggris (Part of Speech); noun, verb, adjective, adverb, preposition, article, pronoun, demonstrative, dan conjunction. Data disajikan dalam tabel verikut ini.

Tabel 1. Klasifikasi Pola Noun Phrase yang Ditemukan

\begin{tabular}{|l|l|l|l|}
\hline No & $\begin{array}{l}\text { Pola Noun } \\
\text { Phrase }\end{array}$ & $\begin{array}{l}\text { Data Temuan } \\
\text { Noun Phrase }\end{array}$ & Jumlah \\
\hline 1 & $\begin{array}{l}\text { Quantifier + } \\
\text { noun }\end{array}$ & $\begin{array}{l}\text { Several } \\
\text { researchers, some } \\
\text { students, some } \\
\text { abstracts }\end{array}$ & 3 \\
\hline 2 & Noun + noun & $\begin{array}{l}\text { topic familiarity, } \\
\text { university } \\
\text { undergraduates, } \\
\text { English } \\
\text { proficiency }\end{array}$ & 3 \\
\hline
\end{tabular}

\begin{tabular}{|c|c|c|c|}
\hline 3 & $\begin{array}{l}\text { Noun }+ \text { noun }+ \\
\text { noun }\end{array}$ & $\begin{array}{l}\text { text format } \\
\text { recognition }\end{array}$ & 1 \\
\hline 4 & $\begin{array}{l}\text { Article }+ \text { noun } \\
+ \text { preposition }+ \\
\text { adv }+ \text { verb }+ \\
\text { noun }+ \text { noun }\end{array}$ & $\begin{array}{l}\text { the use of other } \\
\text { overtly taught } \\
\text { metalinguistic } \\
\text { strategies }\end{array}$ & 1 \\
\hline 5 & $\begin{array}{l}\text { Article + noun } \\
+ \text { noun }\end{array}$ & $\begin{array}{l}\text { the reading } \\
\text { process, the } \\
\text { threshold factor }\end{array}$ & 2 \\
\hline 6 & $\begin{array}{l}\text { Noun }+ \text { noun }+ \\
\text { prep }+ \text { noun }\end{array}$ & $\begin{array}{l}\text { compensatory } \\
\text { facilitators of } \\
\text { comprehending }\end{array}$ & 1 \\
\hline 7 & $\begin{array}{l}\text { Demonstrative } \\
+ \text { noun }+ \text { noun }\end{array}$ & $\begin{array}{ll}\text { This } & \text { research } \\
\text { study } & \\
\end{array}$ & 1 \\
\hline 8 & $\begin{array}{l}\text { Noun }+ \text { prep }+ \\
\text { demonstrative } \\
+ \text { noun }\end{array}$ & $\begin{array}{l}\text { Data from this } \\
\text { study }\end{array}$ & 1 \\
\hline 9 & $\begin{array}{l}\text { Adjective } \quad+ \\
\text { noun }\end{array}$ & $\begin{array}{l}\text { overt instruction, } \\
\text { unexperienced } \\
\text { readers, potential } \\
\text { difficulties, } \\
\text { concise } \\
\text { summaries, } \\
\text { paratextual } \\
\text { information, } \\
\text { academic texts, } \\
\text { further research, } \\
\text { valuable tools }\end{array}$ & 8 \\
\hline 10 & $\begin{array}{ll}\text { Article }+ \\
\text { pronoun }+ \\
\text { noun }+ \text { prep }+ \\
\text { noun }+ \text { noun }\end{array}$ & $\begin{array}{l}\text { the students' use } \\
\text { of compensatory } \\
\text { strategies }\end{array}$ & 1 \\
\hline 11 & Noun & $\begin{array}{l}\text { Conclusions, } \\
\text { results, students, } \\
\text { learners, } \\
\text { abstracts }\end{array}$ & 5 \\
\hline 12 & $\begin{array}{l}\text { Article + noun } \\
+ \text { prep }+ \text { verb }+ \\
\text { prep+ noun }+ \\
\text { noun }\end{array}$ & $\begin{array}{lr}\text { a tendency to } \\
\text { depend } \\
\text { reading processes }\end{array}$ & 1 \\
\hline 13 & $\begin{array}{l}\text { Article }+ \text { adj }+ \\
\text { noun }+ \text { noun }+ \\
\text { prep }+ \text { noun }\end{array}$ & $\begin{array}{l}\text { a limited number } \\
\text { of strategies }\end{array}$ & 1 \\
\hline 14 & $\begin{array}{l}\text { Adj + noun + } \\
\text { conj + article } \\
+ \text { noun }\end{array}$ & $\begin{array}{l}\text { direct interaction } \\
\text { with the text }\end{array}$ & 1 \\
\hline 15 & $\begin{array}{l}\text { Adj }+ \text { conj }+ \\
\text { adj }+ \text { noun }+ \\
\text { noun }\end{array}$ & $\begin{array}{l}\text { Pre and post } \\
\text { reading strategies }\end{array}$ & 1 \\
\hline 16 & $\begin{array}{l}\text { Adj }+ \text { noun }+ \\
\text { prep }+ \text { noun }+ \\
\text { adj }+ \text { noun }\end{array}$ & $\begin{array}{l}\text { full understanding } \\
\text { of field-specific } \\
\text { texts }\end{array}$ & 1 \\
\hline 17 & $\begin{array}{l}\text { Adj }+ \text { noun }+ \\
\text { prep }+ \text { noun }\end{array}$ & $\begin{array}{l}\text { possible reasons } \\
\text { for students, } \\
\text { longer pieces of } \\
\text { writing }\end{array}$ & 2 \\
\hline 18 & $\begin{array}{l}\text { Pronoun }+ \text { adj } \\
+ \text { noun }\end{array}$ & $\begin{array}{l}\text { Their conscious } \\
\text { use }\end{array}$ & 1 \\
\hline 19 & $\begin{array}{l}\text { Adj }+ \text { noun }+ \\
\text { noun }+ \text { noun }\end{array}$ & $\begin{array}{l}\text { Foreign language } \\
\text { university } \\
\text { students, poor } \\
\text { reading } \\
\text { comprehension } \\
\text { skills }\end{array}$ & 2 \\
\hline
\end{tabular}




\begin{tabular}{|c|c|c|c|}
\hline 20 & $\begin{array}{l}\text { Article + noun } \\
+ \text { prep }+ \text { noun } \\
+ \text { article + adj } \\
+ \text { noun }\end{array}$ & $\begin{array}{l}\text { the difficulty of } \\
\text { building the main } \\
\text { idea }\end{array}$ & 1 \\
\hline 21 & $\begin{array}{l}\text { Demonstrative } \\
+ \text { noun }\end{array}$ & $\begin{array}{l}\text { This paper, this } \\
\text { research, this } \\
\text { finding, this study, } \\
\text { those difficulties }\end{array}$ & 5 \\
\hline 22 & $\begin{array}{l}\text { Article }+ \text { noun } \\
+\quad \text { prep }{ }^{+} \\
\text {demonstrative } \\
+ \text { noun }\end{array}$ & $\begin{array}{l}\text { The aim of this } \\
\text { work }\end{array}$ & 1 \\
\hline 23 & $\begin{array}{l}\text { Article }+ \text { adj }+ \\
\text { noun }\end{array}$ & $\begin{array}{l}\text { the different ways, } \\
a \quad \text { strong } \\
\text { disposition, } \quad \text { a } \\
\text { main idea }\end{array}$ & 3 \\
\hline 24 & $\begin{array}{l}\text { Adj }+ \text { adj }+ \\
\text { noun }+ \text { noun }+ \\
\text { noun }\end{array}$ & $\begin{array}{l}\text { poor main idea } \\
\text { building skills }\end{array}$ & 1 \\
\hline 25 & $\begin{array}{l}\text { Article + noun } \\
+ \text { noun }+ \text { prep } \\
+ \text { noun }\end{array}$ & $\begin{array}{l}\text { a threshold level } \\
\text { of } L 2\end{array}$ & 1 \\
\hline 26 & $\begin{array}{l}\text { Adj }+ \text { noun }+ \\
\text { noun }\end{array}$ & skilled L1 readers & 1 \\
\hline 27 & $\begin{array}{l}\text { Pronoun } \quad+ \\
\text { noun }\end{array}$ & $\begin{array}{l}\text { Their competence, } \\
\text { researchers, } \\
\text { opinion }\end{array}$ & 2 \\
\hline 28 & $\begin{array}{l}\text { Article + noun } \\
+ \text { prep }+ \text { noun } \\
+ \text { noun }+ \text { prep } \\
+ \text { adj }+ \text { noun }+ \\
\text { noun }\end{array}$ & $\begin{array}{l}\text { the significance of } \\
\text { FL proficiency for } \\
\text { main idea } \\
\text { building }\end{array}$ & 1 \\
\hline 29 & $\begin{array}{l}\text { Adj }+ \text { noun }+ \\
\text { prep }+ \text { article } \\
+ \text { noun }+ \text { prep } \\
+ \text { noun }\end{array}$ & $\begin{array}{l}\text { direct training in } \\
\text { the use of } \\
\text { strategies }\end{array}$ & 1 \\
\hline 30 & $\begin{array}{l}\text { Noun }+ \text { noun }+ \\
\text { noun }+ \text { prep }+ \\
\text { noun }+ \text { noun }\end{array}$ & $\begin{array}{l}\text { advance reading } \\
\text { hypotheses of } \\
\text { research articles }\end{array}$ & 1 \\
\hline 31 & $\begin{array}{l}\text { Article }+ \text { adj }+ \\
\text { adj }+ \text { noun }\end{array}$ & $\begin{array}{l}\text { the most } \\
\text { significant ideas }\end{array}$ & 1 \\
\hline 32 & $\begin{array}{l}\text { Article + noun } \\
+ \text { prep }+ \text { noun }\end{array}$ & $\begin{array}{l}\text { a conjunction of } \\
\text { result, a corpus of } \\
\text { abstracts }\end{array}$ & 2 \\
\hline 33 & Article + noun & the tools, the fact & 2 \\
\hline 34 & $\begin{array}{l}\text { Adj }+ \text { adj + } \\
\text { noun }\end{array}$ & $\begin{array}{l}\text { Systemic } \\
\text { Functional } \\
\text { Linguistics } \\
\end{array}$ & 1 \\
\hline 35 & $\begin{array}{l}\text { Demonstrative } \\
+ \text { noun }+ \text { noun }\end{array}$ & this text type & 1 \\
\hline 36 & $\begin{array}{l}\text { Article + noun } \\
+ \text { prep }+ \\
\text { article }+ \text { noun }\end{array}$ & $\begin{array}{l}\text { the analysis of the } \\
\text { data }\end{array}$ & 1 \\
\hline 37 & $\begin{array}{l}\text { Noun }+ \text { conj }+ \\
\text { adj }+ \text { noun }\end{array}$ & $\begin{array}{l}\text { lexis with } \\
\text { negative } \\
\text { connotation }\end{array}$ & 1 \\
\hline 38 & $\begin{array}{l}\text { Article + noun } \\
+ \text { prep }+ \text { noun } \\
+ \text { conj }+ \text { adj }+ \\
\text { noun }\end{array}$ & $\begin{array}{l}\text { the fields of Arts } \\
\text { and Applied } \\
\text { Linguistics }\end{array}$ & 1 \\
\hline \multicolumn{3}{|c|}{ TOTAL } & 65 \\
\hline
\end{tabular}

Tabel di atas menunjukkan bahwa terdapat 38 variasi pola noun phrase dari total 65 noun phrase yang dijadikan data penelitian, hal ini berarti noun phrase yang terdapat pada abstrak tersebut sangat beragam dari segi pola kombinasi kata penyusunnya. Ini sangat memungkinkan terjadi mengingat abstrak tersebut ditulis dalam sebuah jurnal internasional yang memang menjadi sebuah wadah bagi pengajar Bahasa Inggris dari berbagai non-native countries untuk menuangkan hasil penelitian mereka dalam proses pengajaran.

Dalam beberapa kasus ditemukan pola noun phrase yang sangat umum seperti pola yang terbentuk dari kombinasi adj+ noun (overt instruction, unexperienced readers, potential difficulties, concise summaries, paratextual information, academic texts, further research, valuable tools). Total terdapat 8 noun phrase atau sekitar yang dibentuk dengan kombinasi kata tersebut. Seperti yang sudah diterangkan sebelumnya, noun phrase bisa saja terdiri dari sebuah kata yang biasanya berbentuk plural dengan menambahkan akhiran noun-s pada akhir kata, seperti yang terdapat pada 5 kata berikut ini: conclusions, results, students, learners, abstracts. Selain itu, cara yang paling sering digunakan dalam membentuk sebuah noun phrase adalah dengan mengombinasikan demonstrative + noun seperti pada frasa This paper, this research, this finding, this study, those difficulties (5 data). Pola ini umumnya digunakan untuk merujuk sebuah noun phrase yang digunakan sebagai subjek maupun objek yang sudah pasti. Kombinasi kata berikutnya yang familiar digunakan dalam penulisan noun phrase pada abstrak-abstrak tersebut adalah quantifier + noun dan noun + noun yang masing-masing memiliki 3 data 
noun phrase yang dibuat dengan kedua pola tersebut (Several researchers, some students, some abstracts dan topic familiarity, university undergraduates, English proficiency). Penggunaan kata ganti kepemilikan (pronoun + noun) juga umum digunakan dalam membentuk noun phrase seperti pada frasa Their competence, researchers' opinion. Hal ini juga berlaku pada kombinasi article + noun yang terdapat pada frasa the tools, the fact. Selain terdiri dari satu atau dua kata, kombinasi kata penyusun noun phrase berikutnya yang ditemukan beberapa kali dalam abstrak adalah penggabungan tiga kata seperti Article + noun + noun pada frasa the reading process, the threshold factor dan kombinasi Article + adj + noun pada frasa the different ways, a strong disposition, a main idea.

Membentuk sebuah noun phrase juga dapat dilakukan dengan menggabungkan lebih dari dua atau tiga kata. Hal ini umumnya digunakan apabila sebuah nomina bersifat umum sehingga membutuhkan beberapa atribut pelengkap yang berfungsi sebagai penjelas. Pada tabel data temuan, dapat dilihat banyak noun phrase yang dibentuk oleh empat kata atau lebih, dan bahkan terdapat noun phrase yang dibentuk oleh kombinasi sembilan kata. Hal ini sah-sah saja selama noun phrase tersebut memiliki satu nomina sebagai Head atau intinya, sebagai contoh, pada data "the significance of FL proficiency for main idea building" noun phrase dibentuk dengan kombinasi Article + noun + preposition + noun + noun + preposition + adjective + noun + noun . Noun phrase yang dibentuk oleh empat atau lebih kombinasi kata jarang sekali ditemukan kesamaan dari segi susunan pola katanya. Hal ini dikarenakan, semakin banyak kombinasi kata yang digunakan dalam membuat sebuah noun phrase, semakin kecil peluang terjadinya pola serupa yang sama persis dari segi urutan kata. Berdasarkan data temuan dapat dilihat rata-rata pola noun phrase yang terdiri dari emat atau lebih kata hanya muncul sebanyak satu kali.

Pada penelitian ini, penulis mengelompokkan pola noun phrase berdasarkan kompleksitas yang dilihat dari jumlah kombinasi kata. Noun phrase yang terdiri dari 1 sampai dengan 3 kata dikelompokkan sebagai pola sederhana, sedangkan noun phrase yang terdiri dari empat atau lebih dikelompokkan sebagai pola kompleks. Berikut ini presentasi jumlah noun phrase yang digunakan sebagai data penelitian:

1. Pola Sederhana yang terdiri dari 15 variasi kombinasi kata: Quantifier + noun, Noun + noun, Noun + noun + noun, Demonstrative + noun + noun, Adjective + noun, Noun-s + Pronoun + adj + noun, Demonstrative + noun, Article + adj + noun, Adj + noun + noun, Pronoun + noun, Article + noun, Adj + adj + noun, Demonstrative + noun + noun. Total jumlah noun phrase yang dibentuk dengan menggunakan pola ini sebanyak 39 item atau $60 \%$ dari total data.

2. Pola Kompleks yang terdiri dari 23 variasi kombinasi kata: Article + noun + preposition $+a d v+v e r b+$ noun + noun, Noun + noun + prep + noun, Noun + prep + demonstrative + noun, Article + pronoun + noun + prep + noun + noun, Article + noun + prep + verb + prep + noun + noun, Article + adj + noun + noun + prep + noun, Adj + noun + conj + article + noun, Adj + conj + adj + noun + noun, Adj + noun + prep + noun + 
adj + noun, Adj + noun + prep + noun, Adj + noun + noun + noun, Article + noun + prep + noun + article + adj + noun, Article + noun + prep + demonstrative + noun, Adj + adj + noun + noun + noun, Article + noun + noun + prep + noun, Article + noun + prep + noun + noun + prep + adj + noun + noun, Adj + noun + prep + article + noun + prep + noun, Noun + noun + noun + prep + noun + noun, Article + adj + adj + noun, Article + noun + prep + noun, Article + noun + prep + article + noun, Noun + conj + adj + noun, Article + noun + prep + noun + conj + adj + noun. Total jumlah noun phrase yang dibentuk dengan pola ini sebanyak 26 item atau $40 \%$ dari total data.

Berdasarkan data di atas dapat dilihat bahwa jika dipandang dari segi kombinasi kalsifikasi kelas kata (part of speech combination), noun phrase yang terdapat pada abstrak cenderung disusun dengan kombinasi adjective + noun yaitu sebanyak 8 data atau $12.31 \%$ dari jumlah total noun phrase. Sedangkan apabila ditinjau dari segi kompleksitas atau banyaknya kombinasi kata yang digunakan, pola noun phrase yang paling banyak digunakan dalam penulisan abstrak pada jurnal internasional ARTESOLESP E-journal. Volume 2, No. 1, November 2012 ISSN 1853-7693 adalah pola sederhana, yaitu kombinasi satu sampai dengan tiga kata dengan jumlah data sebanyak 39 item atau sekitar $60 \%$ dari total kesuluruhan. Hal ini bisa terjadi karena kemudahan dalam mengombinasikan kata yang hanya terdiri dari satu sampai dengan kata, serta keefektifan dalam merujuk atau menjelaskan sebuah noun dengan cara yang lugas dan jelas sehingga gampang dimengerti oleh pembaca.

\section{SIMPULAN}

Setelah menganalisis data noun phrase yang ditemukan dalam abstrak jurnal yang disebutkan di atas, penulis menyimpulkan bahwa dari 65 noun phrase yang ditemukan, sebanyak 39 item atau sekitar $60 \%$ nya dibuat dengan kombinasi sederhana yang terdiri dari 1 sampai dengan 3 kata, dimana 8 item atau $12,31 \%$ di antaranya terdiri dari kombinasi adjective + noun yang menjadi pola kombinasi yang paling sering digunakan. Sedangkan apabila ditinjau dari keberagamannya, pola noun phrase yag digunakan dalam berbagai abstrak artikel penelitian tersebut sangat variatif, terbukti dari jumlah variasinya, yaitu sebanyak 65 noun phrase dibuat dengan 38 variasi kombinasi yang berbeda. Pada kesempatan ini penulis menyarankan kepada para peneliti yang ingin melakukan penelitian sejenis untuk melakukan tinjauan dari sudut pandang lain sebagai tambahan alternatif acuan untuk penelitian-penelitian selanjutnya.

\section{DAFTAR PUSTAKA}

Abney, S. P. (1997). The English Noun Phrase in Its Sententiall Aspect. Disertasi. Massachusetts Institute of Technology.

Aitchison, J. (2003). Teach Yoursel Linguistics. London: Hodder Headline.

Carnie, A. (2012). Syntax, A Generative Introduction. Oxford: Blackwell Publisher.

Coady, J. (2007). Vocabulary Development in Reading Comprehension. Cambridge: CUP. 
Comorovski, I. dan Heusinger, K. V. (2007). Existence: Semantic and Syntax Vol.84. Dordrecht: Springer.

Halliday, M dan Matthiessen, C. (2004): An Introduction to Functional Grammar, third edition. Great Britain: Arnold. 